\title{
Could there be an alternative to the undergraduate marketing student's dissertation?
}

\author{
Emmanuel Mogaji \\ University of Greenwich
}

\section{Background}

Undergraduate students at United Kingdom (UK) universities are expected to write a dissertation at the end of their studies. The dissertation has been described as a seal of undergraduate degree programmes in the UK (Rowley, 2000). Students view it as the "single most substantial, and independently worked upon, piece of work they will undertake while at university" (Webster, Pepper and Jenkins, 2000, p. 72). The emotional rollercoaster for students embarking on their dissertation has been well documented. The experience can sometimes require a tutor to step in and guide the students (Todd, Bannister and Clegg, 2004) and this raises questions about the academic support being provided for them. It may be best to look for an alternative to tutoring to solve this problem and enhance the student experience while maintaining academic quality.

To ease these challenges, various alternatives were presented at the University of Greenwich Business School 2019 Learning and Teaching Festival. The festival explores teaching practices by encouraging: the sharing of effective pedagogies and learning and assessment practice; the exploring of issues regarding student engagement. This piece offers a short and hopefully thought-provoking reflection upon UK student dissertations and support for undergraduate marketing students (Mogaji, 2019a); it raises questions about alternative methods for supporting undergraduate marketing students with their dissertations and acknowledges the challenges that undergraduates face; it identifies key issues that have given rise to questions about the dissertation process and provides alternatives for consideration by tutors and academic staff supporting their students; it also presents the potential advantages and limitations of adopting these alternative methods.

\section{Challenges associated with the undergraduate dissertation}

The support provided to students for the writing of their dissertations is crucial (Heinze and Heinze, 2009), for they experience a variety of challenges during this phase of their undergraduate studies. Silén (2003) notes that the freedom of independent research has the negative effect of 'chaos' and 'cosmos' as students feel uneasy and yet excited about their dissertation journey.

That students, expected to choose a topic for their independent research, often struggle to generate one is considered problematic (Todd, Bannister and Clegg, 2004). These authors found that students frequently find it challenging to produce a research question that is, in fact, researchable; they note that this could be because of lack of experience or limited opportunities and thus call for additional support to help students with the emotional difficulties associated with defining a researchable topic. 
Likewise, Reis (1999) acknowledges the initial anxiety and uncertainty undergraduate students face when deciding what topic they are going to work on and highlights the need to provide them with such help as will enable them to feel prepared for and have commitment to an investigation into relevant and current research. Unlike postgraduate students, finalyear undergraduates have not yet experienced academic research to the level demanded of dissertations.

Considering these concerns about undergraduate dissertations and students' struggle to find 'researchable' ideas, this paper raises the question 'Could there be alternative methods for research question selection?' and offers an answer in the form of a teaching innovation aimed at easing students' anxiety, relieving their sense of pressure and dispelling their uncertainty about choosing their research topic; it also outlines the support provided for students during the process.

\section{Proposed alternatives}

Often, students are expected to select their topics and work with a tutor (a member of the teaching staff) who will support them throughout the process. Since this arrangement has been criticised because of its associated challenges, two alternative methods are presented for consideration.

\section{Call for Papers}

A Call for Paper (CfP) is a document circulated by a professional organisation, such as an academic publisher, journal or conference organiser. It invites individuals with interest in a topic (or a list of topics) to submit their research in the form of original scholarly articles for review and consideration for publication in a journal or book, or for presentation at a conference. A CfP often contains background to and rationale for the request, a literature review, a list of relevant topics - often in bullet points - and also key dates for submissions. For the purposes of an undergraduate dissertation, a tutor could use such a document to provide students with various topics, one of which they might opt to explore; it would act as their guide to research questions current within marketing. Alon (2009) recognises the need to do research that is both feasible and interesting, as that is likely to extend our knowledge significantly. ELMAR (Electronic Marketing List Information) - an academic resource offered by the American Marketing Association to the marketing academic community around the world - is a good platform for accessing CfPs for marketing researchers.

\section{Working in tutors' research areas}

An alternative method would be to invite students to find a topic within their tutor's specific research area. As tutors supporting the students with their dissertations are more likely to have interest in their respective research areas, they could suggest that students consider topics associated with these. For example, a tutor with interest in social media and stakeholder communications strategies might invite students to explore how different sectors communicate with stakeholders on social media. Without giving an exact topic, the tutor could in this way help streamline the search for a research question. Students would then need only to find a sector and explore possible research questions relevant to that context. As many marketing students have trouble grasping the concept of research (Love and Stelling, 2012), making them work with tutors on a specific research area would help 
integrate them into the modalities of research. This method would involve supporting students to develop their research method skills and knowledge and so prepare themselves better for their dissertation. This alternative is not about giving the students a specific topic to research; instead, it is about refining the stream of topics to enable them to make relevant, researchable choices for possible exploration. Fiedler (2014) notes that choosing a topic that is 'research-worthy' is essential for a successful dissertation and that there is a need to pay attention to the broader implications of one's research for various audiences, especially those in academia.

\section{Advantages and limitations of proposed alternatives}

Reflection on past experiences of adopting these alternatives, as well as on feedback from students and staff during the presentation, indicates that there are advantages and limitations that should be considered. One significant advantage of these alternatives is that they give the students a sense of direction for their dissertation: they feel they have a place to start and a path to follow - often a crucial motivation, for once they have that sense of direction, they are spurred on to explore the topic further and conduct their literature review. Staff confirm that students are more motivated when their research topic is finalised. In addition, the tutor is likely to demonstrate greater willingness and eagerness to give support when the student is researching within the tutor's own area of interest; the tutor is better equipped to share readily available information, especially that from relevant and current literature. The student is also aware that more guidance is forthcoming during the process as there is a sense of collaboration and understanding between tutor and student - and feels less pressure and greater reassurance in the presence of available tutor expertise.

Despite these advantages, a couple of limitations must be considered. With regard to the second proposal, tutors need to make sure that their own ideas align with the working principles of the dissertation modules in their universities. This issue was also raised during the presentation. It is, however, important to note that the students are not explicitly provided with research topics and questions but rather with a CfP that is open to different interpretations. In addition, there is no guarantee or expectation that students will be interested in and excited about this process. There are students who may feel they want to continue with the proposal they wrote in their second year, and their wish should be respected.

\section{Conclusion}

This reflective piece raised a question about an alternative approach to the undergraduate dissertation, as presented during the 'Sharing Good Practice' session at the 2019 University of Greenwich Business Faculty Learning and Teaching Festival, where tutors could share their own practices with other colleagues. During the presentations, attending staff were able to corroborate the practices being shared, offer feedback to enhance pedagogical research and discuss how they might implement such methodology in their departments to suppport their undergraduate students. The majority of session participants were unaware of the approaches to the student dissertation presented in this piece and it was certainly fascinating to see their surprised recognition that they have, in their own fields, CfPs from which students might well benefit! 
The piece provides insight into the presentation, which itself highlighted a problem regarding the selection of dissertation topic by marketing undergraduate students; it offers two alternative methods that benefit students by introducing them to current research questions that need answers, making them less anxious about their research topic and helping them to develop skills relevant to their future careers. These alternatives are aimed at tutors working with students who are struggling with selecting a research topic and working on their research methods as they plan for their dissertations.

It is important to note that some students may also be reluctant to work with these ideas, as they may feel that they are too rigid and that they would rather do without them. However, tutors can be flexible with regard to the research areas they offer to the students and can show them additional CfPs to choose from. Tutors must make the students aware of these alternatives to help them find a topic that both aligns with their interests and is researchworthy. Most importantly, they should always support students in their decision.

Students should also be informed that it is not compulsory to choose a topic that has been suggested or made available by the CfPs. Students are still responsible for their learning and should therefore be supported in choosing a topic that they are personally interested in. Reis (1999) argues that finding the ideal research topic is more than just selecting from options provided by tutors. Students may prefer not to select from limited options and therefore it is important to recognise their need to develop an interest of their own choice; they should be supported in developing their research skills and capacity for independent research (Mogaji, 2019b).

The presented alternatives, with their advantages and limitations outlined here, are meant to be optional suggestions for tutors and students and should never act as roadblocks to research freedom. Students are still expected to gain, competently and individually, new knowledge that they find fascinating and self-expressive (Alon, 2009). Tutors should act as guides to the students in exploring alternatives.

\section{Reference list}

Alon, U. (2009) 'How to choose a good scientific problem.' Molecular Cell, 35(6), 726-728. Available at: https://www.ncbi.nlm.nih.gov/pubmed/19782018 (Accessed: 16 December 2019).

Fiedler, S. (2014) 3 Important Things to Consider When Selecting Your Research Topic. Available at:

http://scitechconnect.elsevier.com/3-important-thingsconsider-selecting-research-topicguest-blogger-blair-harrington (Accessed: 02 February 2018).

Heinze, A. and Heinze, B. (2009) 'Blended e-learning skeleton of conversation: Improving formative assessment in undergraduate dissertation supervision.' British Journal of Educational Technology, 40(2), 294-305. Available at: https://doi.org/10.1111/j.14678535.2008.00923.x (Accessed: 16 December 2019). 
Love, E. and Stelling, P. (2012) 'Volcanic Experimentation: Using Mentos and Soda to Teach Causal Research in a Marketing Research Class.' Marketing Education Review, 22(1), $27-$ 32. Available at: https://doi.org/10.2753/MER1052-8008220105 (Accessed: 16 December 2019).

Mogaji, E. (2019) Could there be an alternative to Undergraduate Dissertation? A discussion from the marketing teams. University of Greenwich Business School Learning and Teaching Festival. Greenwich, London: Greenwich Learning \& Teaching Festival. Available at: https://doi.org/10.6084/m9.figshare.10504250.v1 (Accessed: 16 December 2019).

Mogaji, E. (2019b) 'Student Engagement with Linkedln to Enhance Employability.' In: Employability via Higher Education: Sustainability as Scholarship. Cham: Springer, 321-329. Available at: https://doi.org/10.1007/978-3-030-26342-3 21 (Accessed: 16 December 2019).

Reis, R. M. (1999) 'Choosing a Research Topic.' The Chronicle of Higher Education. Available at:

https://www.chronicle.com/article/Choosing-a-Research-Topic/45641 (Accessed: 08 August 2018).

Rowley, J. (2000) 'Thirteen tips for successful supervision of undergraduate dissertations.' Educational Developments, 1(1), 14-15. Available at: http://e-space.mmu.ac.uk/91745/ (Accessed: 16 December 2019).

Silén, C. (2003) Responsibility and independence in learning — what are the role of the educators and the framework of the educational programme? Hinckley, UK: paper presented at the 11th Improving Student Learning, Symposium, 19 September 2003.

Todd, M., Bannister, P. and Clegg, S. (2004) 'Independent inquiry and the undergraduate dissertation: perceptions and experiences of final-year social science students.' Assessment \& Evaluation in Higher Education, 29(3), 335-355. Available at: https://doi.org/10.1080/0260293042000188285 (Accessed: 16 December 2019).

Webster, F., Pepper, D. and Jenkins, A. (2000) 'Assessing the undergraduate dissertation.' Assessment and Evaluation in Higher Education, 25(1), 71-80. Available at: https://doi.org/10.1080/02602930050025042 (Accessed: 16 December 2019). 